\title{
Metallic superhydrophobic surfaces via thermal sensitization
}

Hamed Vahabi, Wei Wang, Ketul C. Popat, Gibum Kwon, Troy B. Holland, and Arun K. Kota

Citation: Appl. Phys. Lett. 110, 251602 (2017); doi: 10.1063/1.4989577

View online: https://doi.org/10.1063/1.4989577

View Table of Contents: http://aip.scitation.org/toc/apl/110/25

Published by the American Institute of Physics

\section{Articles you may be interested in}

Soft, elastic, water-repellent materials

Applied Physics Letters 110, 251605 (2017); 10.1063/1.4985011

Bubble induced flow field modulation for pool boiling enhancement over a tubular surface Applied Physics Letters 110, 251603 (2017); 10.1063/1.4987138

Direct writing of large-area micro/nano-structural arrays on single crystalline germanium substrates using femtosecond lasers

Applied Physics Letters 110, 251901 (2017); 10.1063/1.4986784

The stochastic growth of metal whiskers

Applied Physics Letters 110, 251604 (2017); 10.1063/1.4989852

Bouncing dynamics of impact droplets on the convex superhydrophobic surfaces

Applied Physics Letters 110, 221601 (2017); 10.1063/1.4984230

Plasmonic nanochannel structure for narrow-band selective thermal emitter Applied Physics Letters 110, 251102 (2017); 10.1063/1.4989692

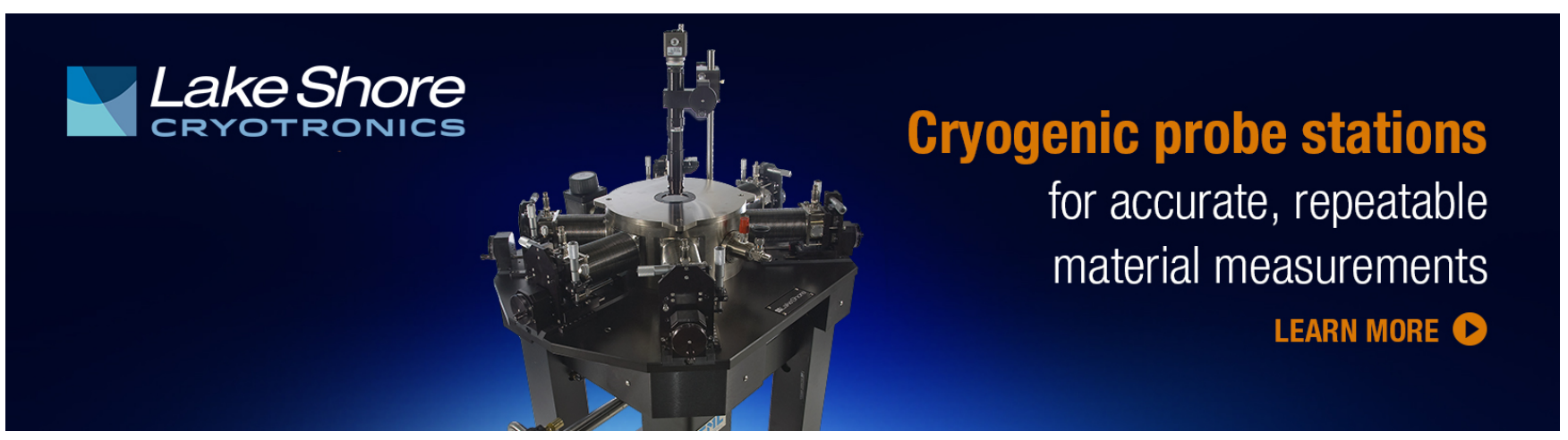




\title{
Metallic superhydrophobic surfaces via thermal sensitization
}

\author{
Hamed Vahabi, ${ }^{1, a)}$ Wei Wang, ${ }^{1, a)}$ Ketul C. Popat, ${ }^{1,2}$ Gibum Kwon, ${ }^{3}$ Troy B. Holland, ${ }^{1}$ \\ and Arun K. Kota ${ }^{1,2, b)}$ \\ ${ }^{1}$ Department of Mechanical Engineering, Colorado State University, Fort Collins, Colorado 80523, USA \\ ${ }^{2}$ School of Biomedical Engineering, Colorado State University, Fort Collins, Colorado 80523, USA \\ ${ }^{3}$ Department of Mechanical Engineering, University of Kansas, Lawrence, Kansas 66045, USA
}

(Received 31 March 2017; accepted 4 June 2017; published online 21 June 2017)

\begin{abstract}
Superhydrophobic surfaces (i.e., surfaces extremely repellent to water) allow water droplets to bead up and easily roll off from the surface. While a few methods have been developed to fabricate metallic superhydrophobic surfaces, these methods typically involve expensive equipment, environmental hazards, or multi-step processes. In this work, we developed a universal, scalable, solvent-free, onestep methodology based on thermal sensitization to create appropriate surface texture and fabricate metallic superhydrophobic surfaces. To demonstrate the feasibility of our methodology and elucidate the underlying mechanism, we fabricated superhydrophobic surfaces using ferritic (430) and austenitic (316) stainless steels (representative alloys) with roll off angles as low as $4^{\circ}$ and $7^{\circ}$, respectively. We envision that our approach will enable the fabrication of superhydrophobic metal alloys for a wide range of civilian and military applications. Published by AIP Publishing.
\end{abstract}

[http://dx.doi.org/10.1063/1.4989577]

Superhydrophobic surfaces (i.e., surfaces extremely repellent to water) allow water droplets to bead up and easily roll off from the surface. ${ }^{1-6}$ Such surfaces have attracted tremendous interest in the past two decades due to their wide range of applications including self-cleaning, ${ }^{7}$ antifouling, ${ }^{8-10}$ and water-oil separation. ${ }^{11,12}$ Superhydrophobic surfaces can be fabricated through a combination of appropriate surface texture and low solid surface energy. ${ }^{1-5}$ Based on this understanding, various techniques have been developed to create appropriate surface texture and fabricate superhydrophobic surfaces with different substrates including ceramics and polymers. ${ }^{13-16}$ Further, a few methods have also been developed to create appropriate surface texture and fabricate metallic superhydrophobic surfaces. ${ }^{17-26}$ However, these methods typically involve expensive equipment (e.g., laser ablation), ${ }^{18-20}$ environmental hazards (e.g., chemical etching), ${ }^{21-25}$ or multi-step processes (e.g., sequential etching with multiple reagents). ${ }^{21,22,24}$ In this work, we developed a universal, scalable, solvent-free, one-step methodology based on thermal sensitization (i.e., selective depletion of one component in the metal alloy at the grain boundaries via heat treatment) to create appropriate surface texture and fabricate metallic superhydrophobic surfaces. To demonstrate the feasibility of our methodology and elucidate the underlying mechanism, we fabricated superhydrophobic surfaces using ferritic (430) and austenitic (316) stainless steels (representative alloys) with roll off angles as low as $4^{\circ}$ and $7^{\circ}$, respectively, for water droplets $(\sim 5 \mu \mathrm{l})$. We envision that our approach will enable fabrication of superhydrophobic metal alloys for a wide range of civilian and military applications.

The primary measure of wetting of a liquid on a nontextured (i.e., smooth) solid surface is the equilibrium (or

\footnotetext{
${ }^{a)} \mathrm{H}$. Vahabi and W. Wang contributed equally to this work.

b) Author to whom correspondence should be addressed: arun.kota@ colostate.edu
}

Young's) contact angle $\theta_{Y} \cdot{ }^{27}$ When the liquid droplet contacts a textured (i.e., rough) solid surface, it displays an apparent contact angle $\theta^{*}$ and can adopt one of the following two configurations to minimize its overall free energy-the fully wetted Wenzel state ${ }^{28}$ or the Cassie-Baxter state. ${ }^{29}$ In the Cassie-Baxter state, pockets of air remain trapped underneath the liquid droplet and the apparent contact angle $\theta^{*}$ can be determined from the Cassie-Baxter relation as ${ }^{29}$

$$
\cos \theta^{*}=f_{s l} \cos \theta_{Y}+f_{l a} \cos \pi .
$$

Here, $f_{s l}$ and $f_{l a}$ are the area fraction of the solid-liquid interface and the liquid-air interface, respectively, underneath the liquid droplet. It is evident from Eq. (1) that for a given value of $\theta_{Y}$ on a non-textured surface, lower $f_{s l}$ and higher $f_{l a}$ lead to higher $\theta^{*}$. Further, lower $f_{s l}$ and higher $f_{l a}$ lead to a lower contact angle hysteresis $\Delta \theta^{*}=\theta_{a d v}^{*}-\theta_{r e c}^{*}$ in the CassieBaxter state. Here, $\theta_{a d v}^{*}$ and $\theta_{r e c}^{*}$ are the apparent advancing and apparent receding contact angles, respectively. ${ }^{30-33}$ The Cassie-Baxter state is preferred for designing superhydrophobic surfaces because it can lead to very high $\theta^{*}$ and very low $\Delta \theta^{*}$, which in turn results in low roll off angle $\omega$ (i.e., the minimum angle by which the surface must be tilted relative to the horizontal for the droplet to roll off). ${ }^{34} \mathrm{~A}$ surface is considered superhydrophobic if it displays $\theta^{*}>150^{\circ}$ and $\Delta \theta^{*}<10^{\circ}$ (or $\omega<10^{\circ}$ ) with high surface tension liquids like water. ${ }^{2-6,35}$ Superhydrophobic surfaces can be fabricated by combining a low solid surface energy (typically $\gamma_{s v}<30 \mathrm{mN} \mathrm{m}^{-1}$ ) surface chemistry with an appropriate surface texture. ${ }^{2-6}$

Thermal sensitization (i.e., selective depletion of one component in the metal alloy at the grain boundaries via heat treatment) is a powerful approach to create surface texture (that is necessary for superhydrophobicity) on virtually any metallic surface. ${ }^{36-41}$ Sensitization begins at the grain boundaries and results in the formation of a rough (or textured) surface without significantly altering the grains themselves. ${ }^{36-41}$ In this work, we fabricated superhydrophobic 
surfaces by combining thermal sensitization of the metallic substrate (to provide the necessary surface texture) with surface modification using a fluorinated silane (to impart the low solid surface energy, see Sec. S1 of supplementary material).

Sensitization temperature $T_{s}$ plays a key role in the sensitization process and thus the formation of surface texture, ${ }^{38-40,42}$ which readily affects the surface wettability. Prior work $^{43-51}$ has demonstrated that heat treatment at low $T_{s}$ results in closely packed, smaller grains; heat treatment at intermediate $T_{s}$ results in widely spaced, larger grains; and heat treatment at high $T_{s}$ results in even larger grains formed via melting-induced merging of adjacent grains. In order to systematically investigate the influence of sensitization temperature on wettability, we heat treated the substrates for $25 \mathrm{~h}$ at different temperatures in the vicinity of their recommended annealing temperature $T_{a}\left(T_{a} \approx 820^{\circ} \mathrm{C}\right.$ for stainless steel 430 and $T_{a} \approx 1040^{\circ} \mathrm{C}$ for stainless steel 316$)^{52,53}$ but lower than their melting temperature $T_{m}\left(T_{m} \approx 1420^{\circ} \mathrm{C}\right.$ for stainless steel 430 and $T_{m} \approx 1370^{\circ} \mathrm{C}$ for stainless steel 316). ${ }^{52,53}$ Subsequently, we modified the sensitized surfaces with a fluorinated silane to impart low solid surface energy ${ }^{2-6}$ and measured the contact angles and roll off angles of water. Note that the contact angles of water droplets on unsensitized and silanized stainless steel 430 and stainless steel 316 are $\theta_{Y}=112^{\circ}$ and $\theta_{Y}=104^{\circ}$ for stainless steel 430 and 316 , respectively (also see Sec. S2 of supplementary material).

When the substrates are sensitized below their corresponding annealing temperatures (i.e., $T_{s}<T_{a}$ ), the receding contact angles of water are relatively low and water droplets cannot roll off (i.e., remain adhered to the surface) on both stainless steel 430 and stainless steel 316 [see Figs. 1(a) and 1(b]. In contrast, when the substrates are sensitized slightly above their corresponding annealing temperatures (i.e., $T_{s}>T_{a}$ ), there is a significant increase in the receding contact angle, a significant decrease in the contact angle hysteresis, and a significant decrease in the roll off angles for water, rendering the surfaces superhydrophobic. The experimentally measured roll off angles match reasonably well with the predictions based on the work by Furmidge ${ }^{54}$ but are consistently higher than the predicted values. This can be addressed by predicting the roll off angles using Tadmor's approach, which is based on the scaling arguments put forth by Shanahan and de Gennes. (see Sec. S3 of supplementary material). ${ }^{5-61}$ In addition to water, the surfaces are superrepellent to a wide variety of aqueous liquids [Figs. 1(a) and 1(b) insets; also see Movie S1 and Movie S2 of supplementary material]. However, when the substrates are sensitized above their corresponding annealing temperatures, approaching their corresponding melting temperatures (i.e., $T_{s}>T_{a}$ and $T_{s} \rightarrow T_{m}$ ), the receding contact angles decreased, the contact angle hysteresis increased for water, and water droplets could no longer roll off from the surface.

In order to understand the influence of $T_{s}$ on the surface texture of the stainless steel substrates that in turn governs the wettability, we characterized the morphology of surfaces using a scanning electron microscope (SEM) and the roughness of surfaces using an optical profilometer (see Sec. S1 of supplementary material). Heat treatment at low $T_{s}$ in the vicinity of $T_{a}$ (i.e., $T_{s}<T_{a}$ ) resulted in closely packed, smaller grains with $\sim 1 \mu \mathrm{m}$ spike-like texture on the surface [see Figs. 2(a) and 2(d)], which led to low roughness (e.g., the root mean square roughness $R_{r m s}=2.8 \pm 0.1 \mu \mathrm{m}$ for stainless steel 430 at $T_{s}=750^{\circ} \mathrm{C}$ and $R_{r m s}=3.4 \pm 0.2 \mu \mathrm{m}$ for stainless steel 316 at $T_{s}=950^{\circ} \mathrm{C}$ ). This in turn led to $\theta_{a d v}^{*}$ $>\theta_{\mathrm{Y}}$ but very high $\Delta \theta^{*}$ [see Figs. 1(a) and 1(b)], indicating that the water droplet perhaps adopted a Cassie-Baxter with high $f_{s l}$ and low $f_{l a}$. In contrast, heat treatment at an intermediate $T_{s}$ (i.e., $T_{s} \geq T_{a}$, but below the melting temperature $T_{m}$, i.e., $T_{s}<T_{m}$ ) resulted in widely spaced, larger grains with $\sim 10-30 \mu \mathrm{m}$ bead-like coarser texture for stainless steel 430 and $\sim 20-50 \mu \mathrm{m}$ bead-like coarser texture for stainless steel 316 [see Figs. 2(b) and 2(e)]. Further, it consisted of a finer texture [see insets in Figs. 2(b) and 2(e)] that perhaps arose from the selective depletion of chromium and enrichment of iron within each grain or at the grain boundaries (see Sec. S4 of supplementary material). This hierarchical structure (coarser texture coupled with the finer texture) resulted in high roughness (e.g., $R_{r m s}=11.4 \pm 0.9 \mu \mathrm{m}$ for stainless steel 430 at $T_{s}=850^{\circ} \mathrm{C}$ and $R_{r m s}=23.9 \pm 1.1 \mu \mathrm{m}$ for stainless steel 316 at $T_{s}=1100^{\circ} \mathrm{C}$ ). This in turn led to very high $\theta_{a d v}^{*}$ and very low $\Delta \theta^{*}$ [see Figs. 1(a) and 1(b)], indicating that the water droplet adopted a Cassie-Baxter state with low $f_{s l}$ and high $f_{\text {la }}$. However, heat treatment at a high $T_{s}$ (i.e., $T_{s} \rightarrow$
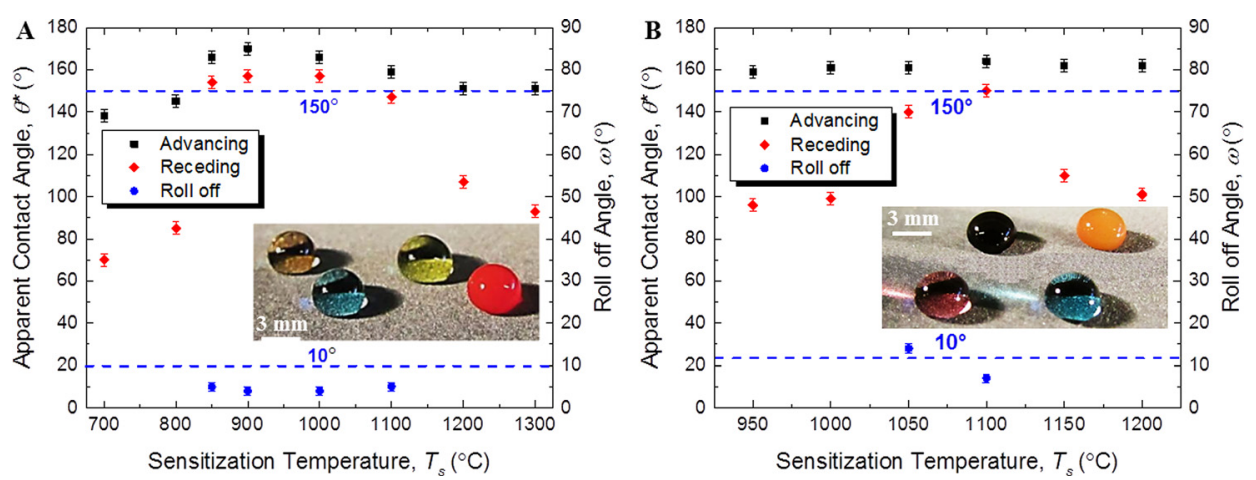

FIG. 1. (a) Water contact angles and roll off angles as a function of the sensitization temperature for stainless steel 430; the inset shows droplets of aqueous liquids - diluted tomato ketchup (red), tea (green), DI water (blue), and coca cola (light brown) beading up on superhydrophobic stainless steel 430 (sensitization temperature $T_{s}=850{ }^{\circ} \mathrm{C}$ and sensitization time $t_{s}=25 \mathrm{~h}$ ). (b) Water contact angles and roll off angles as a function of the sensitization temperature for stainless steel 316; the inset shows droplets of aqueous liquids—soy sauce (dark brown), strawberry juice (pink), coffee (orange-brown), and DI water (blue) beading up on superhydrophobic stainless steel 316 (sensitization temperature $T_{s}=1100^{\circ} \mathrm{C}$ and sensitization time $t_{s}=25 \mathrm{~h}$ ). 

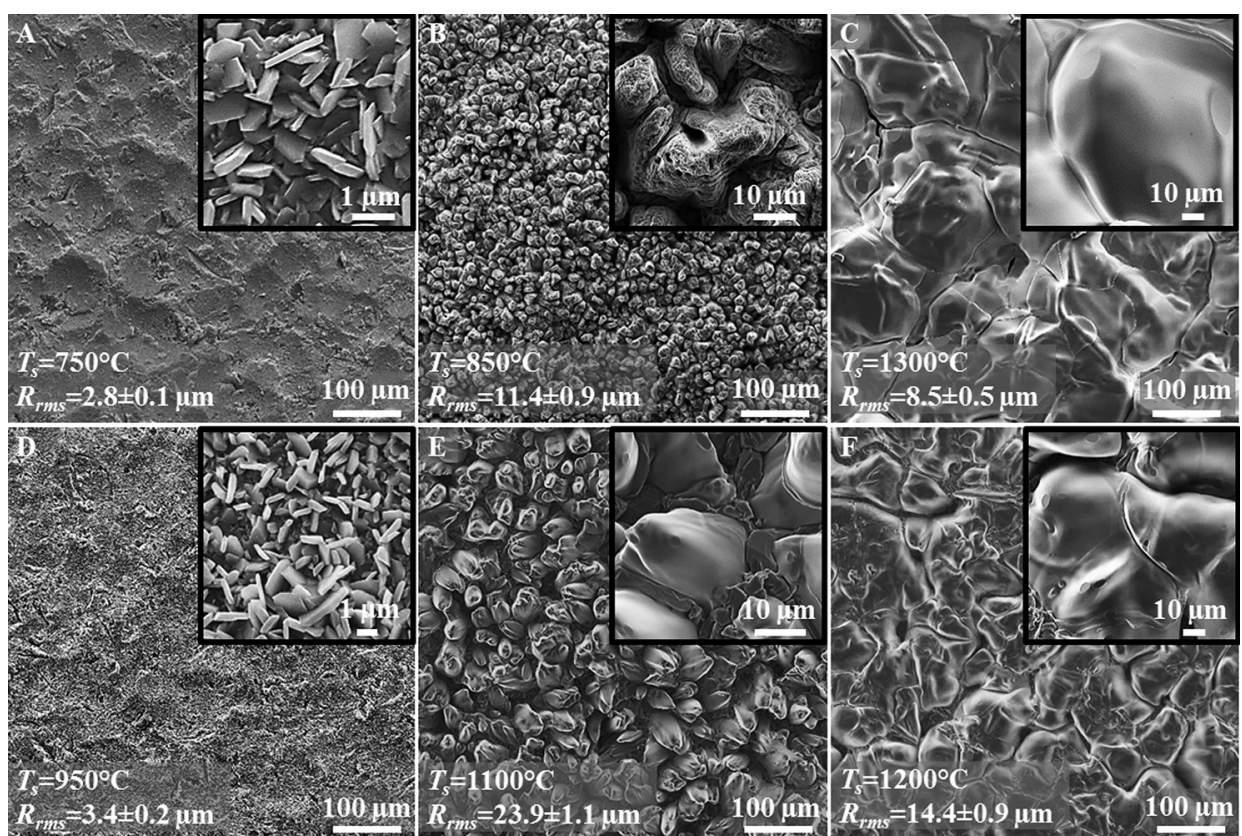

FIG. 2. (a)-(c) Evolution of surface texture with sensitization temperature for stainless steel 430 . (d)-(f) Evolution of surface texture with sensitization temperature for stainless steel 316. Insets show the surface texture at higher magnification.
$T_{m}$ ) resulted in even larger grains, with $\sim 100-500 \mu \mathrm{m}$ shallow features on stainless steel 430 and $\sim 100-300 \mu \mathrm{m}$ shallow features on stainless steel 316 [see Figs. 2(c) and 2(f)], formed via melting-induced merging of adjacent grains. The shallower features resulted in low roughness (e.g., $R_{r m s}=8.5$ $\pm 0.5 \mu \mathrm{m}$ for stainless steel 430 at $T_{s}=1300^{\circ} \mathrm{C}$ and $R_{r m s}$ $=14.4 \pm 0.9 \mu \mathrm{m}$ for stainless steel 316 at $T_{s}=1200^{\circ} \mathrm{C}$ ). This in turn led to $\theta_{a d v}^{*}>\theta_{Y}$ but very high $\Delta \theta^{*}$ [similar to low $T_{s}$; see Figs. 1(a) and 1(b)], indicating that the water droplet perhaps adopted a Cassie-Baxter with high $f_{s l}$ and low $f_{l a}$.

In addition to sensitization temperature, the sensitization time $t_{s}$ also plays a key role in altering the surface texture of the metallic alloy substrates. ${ }^{38-42,62}$ Prior work ${ }^{43,44,48-51,63,64}$ has demonstrated that heat treatment of a substrate at an intermediate $T_{s}$ results in widely spaced, larger grains that are non-uniform at low $t_{s}$; uniform at sufficiently high $t_{s}$; and no significant change in morphology at even higher $t_{s}$. In order to systematically investigate the influence of $t_{s}$ on the surface texture and consequently wettability, we heat treated our substrates for different times at intermediate $T_{s}$ that resulted in superhydrophobicity (i.e., $T_{s}=850{ }^{\circ} \mathrm{C}$ for stainless steel 430 and $T_{s}=1100^{\circ} \mathrm{C}$ for stainless steel 316). Subsequently, we modified the heat treated surfaces with a fluorinated silane to impart low solid surface energy and measured the contact angles and roll off angles of water. Heat treatment at low $t_{s}$ (i.e., $t_{s}<25 \mathrm{~h}$ for stainless steel 430 and $t_{s}<15 \mathrm{~h}$ for stainless 316 ) resulted in $<5 \mu \mathrm{m}$ bead-like texture that is not uniform across the entire surface [see Figs. 3(a) and 3(d) and the insets]. This resulted in low roughness (e.g., $R_{r m s}=3.1 \pm 0.1 \mu \mathrm{m}$ for stainless steel 430
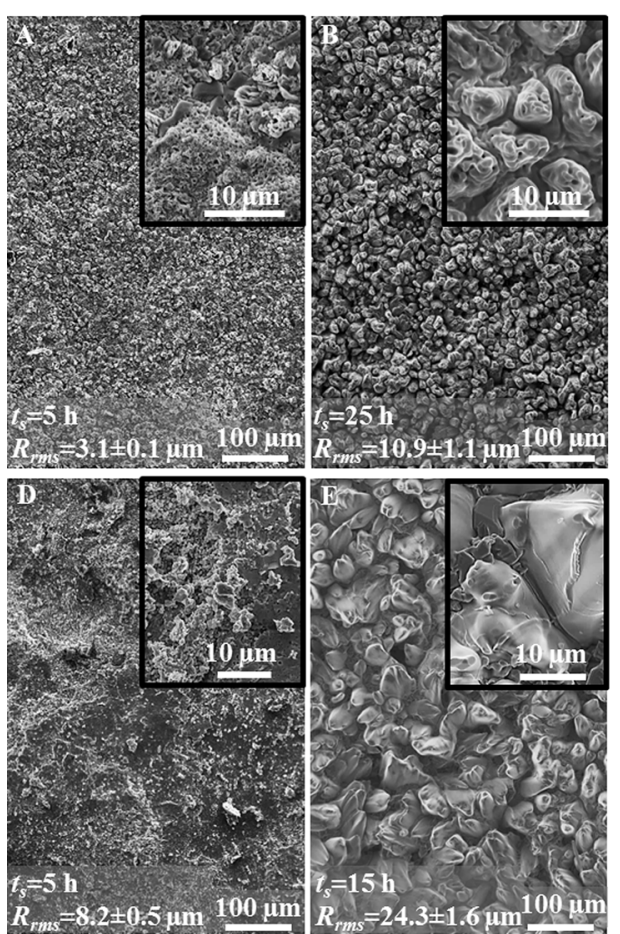
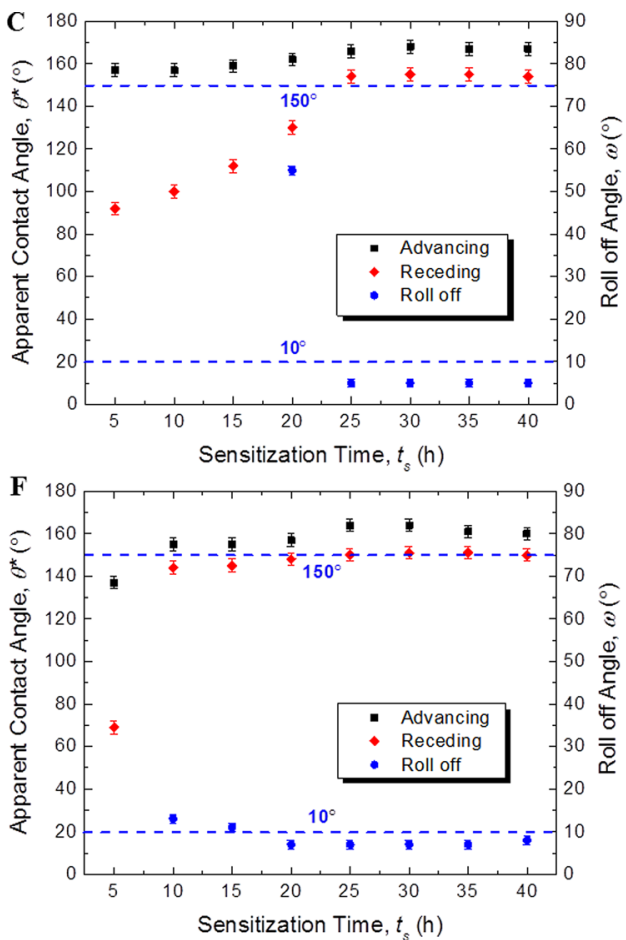

FIG. 3. (a) and (b) Evolution of surface texture with sensitization time for stainless steel 430. Insets show the surface texture at higher magnification. (c) Water contact angles and roll off angles as a function of the sensitization time for stainless steel 430. (d) and (e) Evolution of surface texture with sensitization time for stainless steel 316. Insets show the surface texture at higher magnification. (f) Water contact angles and roll off angles as a function of the sensitization time for stainless steel 316. 
and $R_{r m s}=8.2 \pm 0.5 \mu \mathrm{m}$ for stainless steel 316). This in turn led to $\theta_{a d v}^{*}>\theta_{Y}$ but very high $\Delta \theta^{*}$ [see Figs. 3(c) and 3(f)], indicating that the water droplet perhaps adopted a CassieBaxter state with high $f_{s l}$ and low $f_{l a}$. In contrast, heat treatment at sufficiently high $t_{s}$ (i.e., $t_{s}=25 \mathrm{~h}$ for stainless steel 430 and $t_{s}=15 \mathrm{~h}$ for stainless 316 ) resulted in widely spaced, larger grains with uniformly distributed $\sim 10-30 \mu \mathrm{m}$ beadlike coarser texture for stainless steel 430 and $\sim 20-50 \mu \mathrm{m}$ bead-like coarser texture for stainless steel 316 [see Figs. $3(\mathrm{~b})$ and $3(\mathrm{e})]$. Further, it consisted of a finer texture [see insets in Figs. 3(b) and 3(e)] that perhaps arose from the selective depletion of chromium and enrichment of iron within each grain or at the grain boundaries (see Sec. S4 of supplementary material). This hierarchical structure (coarser texture coupled with the finer texture) resulted in high roughness (e.g., $R_{r m s}=10.9 \pm 1.1 \mu \mathrm{m}$ for stainless steel 430 at $t_{s}=25 \mathrm{~h}$ and $R_{r m s}=24.3 \pm 1.6 \mu \mathrm{m}$ for stainless steel 316 at $\left.t_{s}=15 \mathrm{~h}\right)$. This in turn led to very high $\theta_{a d v}^{*}$ and very low $\Delta \theta^{*}$ [see Figs. 3(c) and 3(f)], indicating that the water droplet adopted a Cassie-Baxter state with low $f_{s l}$ and high $f_{l a}$. A further increase in $t_{s}$ (i.e., i.e., $t_{s}>25 \mathrm{~h}$ for stainless steel 430 and $t_{s}>15 \mathrm{~h}$ for stainless 316 ) does not change the surface morphology and thus wettability significantly [see Figs. 3(c) and 3(f)].

In summary, we fabricated textured ferritic and austenitic stainless steel surfaces (representative metallic alloys with different chemical compositions and microstructures) via a universal, scalable, solvent-free, one-step methodology based on thermal sensitization. In order to obtain the optimum surface texture necessary for superhydrophobicity, we systematically investigated the influence of the key sensitization parameters - sensitization temperature and sensitization time- on the surface texture. The combination of the optimum surface texture with low solid surface energy imparted by surface modification with a fluorinated silane resulted in extreme repellence to a variety of aqueous liquids. We envision that our approach will enable fabrication of superhydrophobic alloys for a wide range of civilian and military applications.

See supplementary material for Sec. S1: Experimental Details, Sec. S2: Surface Morphology and Wettability of Unsensitized and Silanized Surfaces, Sec. S3: Roll off angles, Sec. S4: Characterization of Chemical Composition, Movie S1: Water droplet $(\sim 5 \mu \mathrm{l})$ bouncing on superhydrophobic stainless steel 430, and Movie S2: Water droplet ( $\sim 5 \mu \mathrm{l}$ ) bouncing on superhydrophobic stainless steel 316.

We thank Colorado Office of Economic Development and International Trade for financial support under award EDA 14-246.

${ }^{1}$ K. Liu, X. Yao, and L. Jiang, Chem. Soc. Rev. 39, 3240 (2010).

${ }^{2}$ S. Nishimoto and B. Bhushan, RSC Adv. 3, 671 (2013).

${ }^{3}$ B. Bhushan and Y. C. Jung, Prog. Mater. Sci. 56, 1 (2011).

${ }^{4}$ A. K. Kota, W. Choi, and A. Tuteja, MRS Bull. 38, 383 (2013).

${ }^{5}$ A. K. Kota, G. Kwon, and A. Tuteja, NPG Asia Mater. 6, e109 (2014).

${ }^{6}$ A. K. Kota, J. M. Mabry, and A. Tuteja, Surf. Innovations 1, 71 (2013).

${ }^{7}$ T. Sun, L. Feng, X. Gao, and L. Jiang, Acc. Chem. Res. 38, 644 (2005).

${ }^{8}$ C. M. Magin, S. P. Cooper, and A. B. Brennan, Mater. Today 13, 36 (2010).

${ }^{9}$ G. D. Bixler and B. Bhushan, Crit. Rev. Solid State Mater. Sci. 40, 1 (2015).
${ }^{10}$ S. Movafaghi, V. Leszczak, W. Wang, J. A. Sorkin, L. P. Dasi, K. C. Popat, and A. K. Kota, Adv. Healthcare Mater. 6, 1600717 (2017).

${ }^{11}$ G. Kwon, A. Kota, Y. Li, A. Sohani, J. M. Mabry, and A. Tuteja, Adv. Mater. 24, 3666 (2012).

${ }^{12}$ F. Zhang, W. B. Zhang, Z. Shi, D. Wang, J. Jin, and L. Jiang, Adv. Mater. 25, 4192 (2013).

${ }^{13}$ P. A. Levkin, F. Svec, and J. M. J. Frechet, Adv. Funct. Mater. 19, 1993 (2009).

${ }^{14}$ H. Vahabi, W. Wang, S. Movafaghi, and A. K. Kota, ACS Appl. Mater. Interfaces 8, 21962 (2016).

${ }^{15}$ W. Wang, K. Lockwood, L. M. Boyd, M. D. Davidson, S. Movafaghi, H. Vahabi, S. Khetani, and A. K. Kota, ACS Appl. Mater. Interfaces 8, 18664 (2016).

${ }^{16}$ G. Azimi, R. Dhiman, H. M. Kwon, A. T. Paxson, and K. K. Varanasi, Nat. Mater. 12, 315 (2013).

${ }^{17}$ L. J. Chen, M. Chen, H. D. Zhou, and J. M. Chen, Appl. Surf. Sci. 255, 3459 (2008).

${ }^{18}$ A. M. Emelyanenko, F. M. Shagieva, A. G. Domantovsky, and L. B. Boinovich, Appl. Surf. Sci. 332, 513 (2015).

${ }^{19}$ B. Wu, M. Zhou, J. Li, X. Ye, G. Li, and L. Cai, Appl. Surf. Sci. 256, 61 (2009).

${ }^{20}$ A. Y. Vorobyev and C. Guo, Laser Photonics Rev. 7, 385 (2013).

${ }^{21}$ L. Li, V. Breedveld, and D. W. Hess, ACS Appl. Mater. Interfaces 4, 4549 (2012).

${ }^{22}$ S. S. Latthe, P. Sudhagar, A. Devadoss, A. M. Kumar, S. Liu, C. Terashima, K. Nakata, and A. Fujishima, J. Mater. Chem. A 3, 14263 (2015).

${ }^{23}$ M. Ruan, W. Li, B. Wang, B. Deng, F. Ma, and Z. Yu, Langmuir 29, 8482 (2013).

${ }^{24}$ Q. Wang, B. Zhang, M. Qu, J. Zhang, and D. He, Appl. Surf. Sci. 254, 2009 (2008).

${ }^{25}$ M. Qu, B. Zhang, S. Song, L. Chen, J. Zhang, and X. Cao, Adv. Funct. Mater. 17, 593 (2007).

${ }^{26}$ D. Lei, J. Benson, A. Magasinski, G. Berdichevsky, and Y. Gleb, Science 355, 267 (2017).

${ }^{27}$ T. Young, Philos. Trans. R. Soc. London 95, 65 (1805).

${ }^{28}$ R. N. Wenzel, Ind. Eng. Chem. 28, 988 (1936).

${ }^{29}$ A. B. Cassie and S. Baxter, Trans. Faraday Soc. 40, 546 (1944).

${ }^{30}$ L. Gao and T. J. McCarthy, Langmuir 22, 2966 (2006).

${ }^{31}$ N. A. Patankar, Langmuir 19, 1249 (2003).

${ }^{32}$ W. Wang, J. Salazar, H. Vahabi, A. Joshi-Imre, W. E. Voit, and A. K. Kota, Adv. Mater. 2017, 1700295.

${ }^{33}$ S. Movafaghi, W. Wang, A. Metzger, D. D. Williams, J. D. Williams, and A. K. Kota, Lab Chip 16, 3204 (2016).

${ }^{34}$ K. K. Varanasi, T. Deng, M. F. Hsu, and N. Bhate, "Design of superhydrophobic surfaces for optimum roll-off and droplet impact resistance" paper presented at the ASME 2008 International Mechanical Engineering Congress and Exposition, 2008.

${ }^{35}$ A. Lafuma and D. Quere, Nat. Mater. 2, 457 (2003).

${ }^{36}$ F. Wilson, Br. Corros. J. 6, 100 (1971).

${ }^{37}$ P. C. S. Wu, Sensitization, Intergranular Attack, Stress Corrosion Cracking, and Irradiation Effects on the Corrosion of Iron-Chromium-Nickel Alloys (Westinghouse Electric Corp., Madison, PA, USA,) (1978).

${ }^{38}$ A. P. Bond and E. A. Lizlovs, J. Electrochem. Soc. 116, 1305 (1969).

${ }^{39}$ C. S. Tedmon, D. A. Vermilyea, and J. H. Rosolowski, J. Electrochem. Soc. 118, 192 (1971).

${ }^{40}$ A. S. Lima, A. M. Nascimento, H. F. Abreu, and P. de Lima-Neto, J. Mater. Sci. 40, 139 (2005).

${ }^{41}$ P. J. Gellings and M. A. De Jongh, Corros. Sci. 7, 413IN5417 (1967).

${ }^{42}$ J. S. Armijo, Corrosion 24, 24 (1968).

${ }^{43}$ M. Shirdel, H. Mirzadeh, and M. Parsa, Mater. Charact. 97, 11 (2014).

${ }^{44}$ R. D. MacPherson and D. J. Srolovitz, Nature 446, 1053 (2007).

${ }^{45}$ Q. Sha and Z. Sun, Mater. Sci. Eng., A 523, 77 (2009).

${ }^{46}$ Z. Huda and T. Zaharinie, J. Alloys Compd. 478, 128 (2009).

${ }^{47}$ Y. Xu, D. Tang, Y. Song, and X. Pan, Mater. Des. 36, 275 (2012).

${ }^{48}$ B. N. Kim, K. Hiraga, and K. Morita, Mater. Trans. 44, 2239 (2003).

${ }^{49}$ J. Mizera, J. W. Wyrzykowski, and K. J. Kurzydłowski, Mater. Sci. Eng. A 104, 157 (1988).

${ }^{50}$ J. B. Koo and D. Y. Yoon, Metall. Trans. A. 32, 1911-1926 (2001).

${ }^{51}$ G. Grest, M. Anderson, D. J. Srolovitz, and A. Rollett, Scr. Metall. Mater. 24, 661 (1990).

${ }^{52}$ J. R. Davis, Stainless Steels (ASM international, USA, 1994).

${ }^{53}$ Specialty Steel Industry of the United States, Specialty Steel Institute of North America, Nickel Development Institute (Canada), American Iron, Steel Institute. Design Guidelines for the Selection and Use of Stainless Steel (Specialty Steel Industry of the United States, 1993).

${ }^{54}$ C. G. L. Furmidge, J. Colloid Sci. 17, 309 (1962). 
${ }^{55}$ R. Tadmor, Soft Matter 7, 1577 (2011).

${ }^{56}$ A. Carré, J. C. Gastel, and M. E. Shanahan, Nature 379, 432 (1996).

${ }^{57}$ H. E. N'guessan, A. Leh, P. Cox, P. Bahadur, R. Tadmor, P. Patra, R. Vajtai, P. M. Ajayan, and P. Wasnik, Nat. Commun. 3, 1242 (2012).

${ }^{58}$ R. Tadmor, P. Bahadur, A. Leh, H. E. N'guessan, R. Jaini, and L. Dang, Phys. Rev. Lett. 103, 266101 (2009).

${ }^{59}$ W. Xu, J. Xu, X. Li, Y. Tian, C. H. Choi, and E. H. Yang, Soft Matter 12, 6902 (2016).
${ }^{60} \mathrm{R}$. Tadmor, Langmuir 29, 15474 (2013).

${ }^{61}$ A. Leh, H. E. N'guessan, J. Fan, P. Bahadur, R. Tadmor, and Y. Zhao, Langmuir 28, 5795 (2012).

${ }^{62}$ E. Almanza and L. Murr, J. Mater. Sci. 35, 3181 (2000).

${ }^{63}$ A. Rollett, D. J. Srolovitz, and M. Anderson, Acta Metall. 37, 1227 (1989).

${ }^{64}$ R. Abbaschian and R. E. Reed-Hill, Physical Metallurgy Principles (Cengage Learning, 2008). 